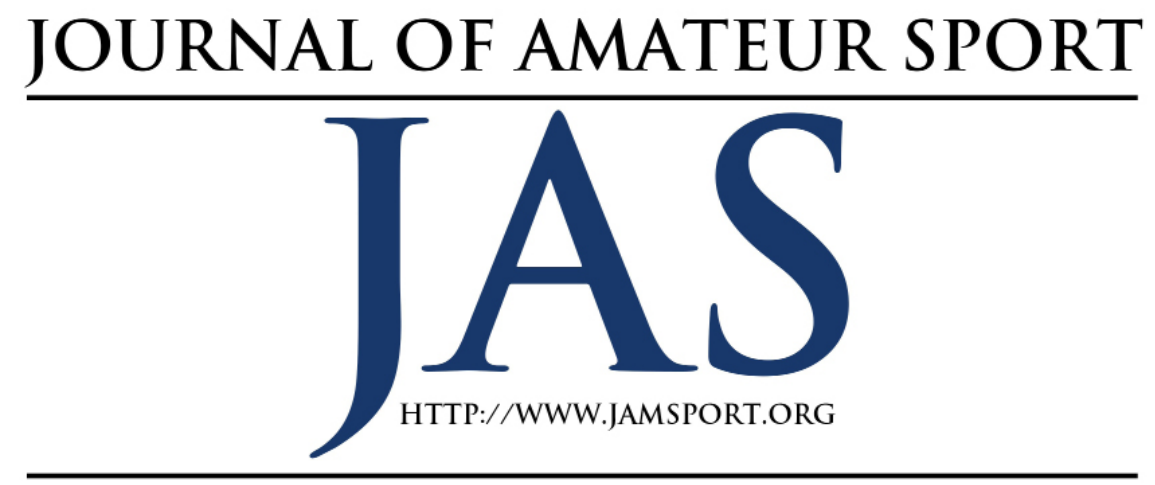

\title{
Challenges of an established amateur sport: Exploring how wheelchair basketball grows and thrives through a sport development lense
}

\author{
Joshua R. Pate ${ }^{1}$ \\ Danielle Bragale ${ }^{1}$
}

${ }^{1}$ James Madison University

Wheelchair basketball has been played in the United States for more than 70 years, and the National Wheelchair Basketball Association (NWBA) governing body has professionalized the sport to some extent with a league and culminating annual championship for its eight divisions. However, teams continue to face challenges that characteristically align with those of amateur sport in addressing recruiting and retaining athletes. The purpose of this study was to examine how the amateur sport of wheelchair basketball grows and thrives in recruiting and retaining participants. Green's (2005) theory of sport development was chosen as the lens for this study because of its focus on establishment of a sport for sustainability through athlete participation. An online open-ended questionnaire was sent to all 139 NWBA team contacts, with 28 responses representing multiple divisions within the league. Findings revealed that funding is the biggest challenge as teams offered little support for tournament travel or financial rewards for athletes. Teams recruited athletes through social connections and community presence, but offered little structure for their means of retaining athletes. These findings show the NWBA teams operate with challenges akin to amateur sport due to uncertainty of funding and athlete sustainability.

\section{Introduction}

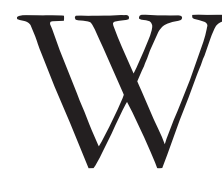

heelchair basketball began

in 1946 as a physical activity option for injured World War
II veterans completing rehabilitation in California and Massachusetts (NWBA, n.d.a). Recreational contests were held between veterans and doctors at 
Table 1

\section{NWBA divisions}

Division

Teams

Division I

Division II

Division III

53

Intercollegiate

16

Women's Division

Total

rehabilitation facilities until a team from Birmingham, CA, traveled to the Corona Naval Station almost 30 miles away for what is recognized as the first contest between two wheelchair basketball teams (NWBA, n.d.a). The sport grew within Veterans Administration hospitals, and in 1948 the National Wheelchair Basketball Association (NWBA) was organized under the direction of Tim Nugent at the University of Illinois (Strohkendl, 1996).

The NWBA serves as the governing body of competitive wheelchair basketball in the United States, with eight divisions: Junior Division-Prep, Junior Division-Varsity, Division I, Division II, Division III, Intercollegiate Men's, Intercollegiate Women's, and Women's. As of 2018 there were 139 teams competing in the NWBA. Globally, wheelchair basketball continues to grow among people with disabilities and is played by more than 100,000 people in more than 80 countries (Hutzler, Barda, Mintz, \& Hayosh, 2016).

The sport is an attractive option for athletes with physical disabilities seeking competition and athletic demands due to a number of rules similarities to ambulatory basketball. It is also a popular programming element for inclusive sport organizations that offer sport and recreation for people with physical disabilities although equipment can cost as much as $\$ 2,000$ per sport wheelchair.

While the sport has grown since its inception in 1946 in the United States and the NWBA has established structure for the sport in some ways, an aging demographic in specific communities with small populations and geographic

Table 2

States/territory represented in the current study State/Territory Number of Teams Alabama 1

Arizona 2

California 2

Connecticut 1

Florida 2

Illinois 4

Kentucky 1

Maryland 1

Minnesota 1

Missouri 3

Nevada 1

Texas 1

Utah 1

Virginia 1

Washington 2

Wisconsin 1

* Puerto Rico 1

* Washington D.C. 2

* Denotes U.S. territory 
limitations presents challenges for the longevity of the sport's development (Hutzler et al., 2016). College campuses around the United States have slowly adopted wheelchair basketball at the recreational, intramural, club sport, and varsity sport levels. The University of Illinois's varsity program was the first to offer wheelchair basketball as a competitive option for students.

In all, 16 teams at 11 universities offered varsity wheelchair basketball competing in the NWBA Intercollegiate division as of 2018. The NWBA, however, is far broader than a college campus and includes teams that have no support system from a university or rehabilitation center. Still, the challenges that NWBA teams face as well as approaches to recruiting and retaining athletes to play competitive wheelchair basketball have not been explored. It is important to identify and examine these challenges teams face to give the league and teams a better grasp on establishing a pipeline for future athletes and keeping existing athletes. Thus, the purpose of this study was to examine how the amateur sport of wheelchair basketball grows and thrives in recruiting and retaining participants..

\section{Literature Review} Disability Sport Barriers

Disability sport faces a myriad of challenges and barriers within the general public sports sphere. Rimmer (2015) identified five categories of barriers to physical activity for people with disabilities: (a) unemployment or underemployment; (b) inability to walk outdoors due to terrain and safety; (c) inability to walk long periods of time for health benefits; (d) transportation to community fitness facilities; and (e) lack of fitness facilities with accessible equipment, classes, programs, or trained staff to adapt programs and services. These barriers are a mix of both structural and psychological barriers.

Previously, however, Rimmer, Riley, Wang, Rauworth, \& Jurkowski (2004) identified 10 categories of barriers related to access to and participation in physical activity that were primarily structural barriers: (a) build and natural environment; (b) cost/economic; (c) equipment; (d) guidelines, codes, regulations, and laws; (e) information; (f) policies and procedures; and $(\mathrm{g})$ resource availability. Additionally, Rimmer et al. identified psychological barriers such as emotional/psychological; knowledge, education, and training; and perceptions and attitudes. Comprehensively, these categories provide a framework for common barriers in disability sport and specifically wheelchair basketball.

Structural barriers are mostly related to physical space such as access to a facility, equipment access or existence, and funding for disability sport opportunities (Wilson \& Khoo, 2013). One commonly identified barrier for athletes with disabilities is accessing transportation to a facility for those needing to travel long distances for either training or competition (Kean, 
Gray, Verdonck, Burkett, \& Oprescu, 2017). Transportation has been noted as a major factor that influences participation of athletes with disabilities (Cottingham, Carroll, Lee, Shapiro, \& Pitts, 2016; Darcy, Lock, \& Taylor, 2016). Cottingham et al. (2016) also found that assistive transportation devices such as the wheelchair can limit an athlete's access to exercising.

Equipment access is another common structural barrier for athletes with disabilities (Rimmer et al., 2004). A lack of proper adaptive sports equipment for athletes prevents full inclusion of participants (Burkett, 2010). More specifically, standard assistive devices may not appropriately accommodate all athletes due to the variance of disability (Burkett, 2010). Athletes with high support needs (e.g., power and manual wheelchair users) have identified that access to proper equipment is a barrier to their athletic performance (Darcy et al., 2016). While access to equipment is limiting, it is the cost of adaptive equipment that prevents access as athletes with disabilities often do not have the financial resources for highperformance adapted equipment equal to their high-performing expectations and achievements (Kean et al., 2017).

Thus, funding has emerged as a third common category of structural barriers for disability sport (Rimmer et al., 2004). Cottingham et al. (2016) note that because people with disabilities are often underemployed, it hinders their ability to financially support their sport participation due to expenses of transportation and equipment. Even within the NWBA, athletes may be responsible for their own transportation and equipment expenses (e.g., sport chair). A way to offset funding gaps is sponsorship, but Kean et al. (2017) found that American athletes have difficulty securing wheelchair sponsorship even at the highest level of competition.

Other structural barriers have been found to prevent or stymie disability sport participation, including organization and structure of disability sport (Thomas \& Guett, 2014), access to sport websites (Cottingham et al., 2016) and even an increasingly aging population of participants (e.g., limitations due to age; $\mathrm{Ng}, 2007)$. Thomas and Guett (2014) found that disability sport organization and structures are problematic across Europe because they operate in silos divided by issue rather than moving forward as one united movement. Still, legislation in the United States such as the Americans with Disabilities Act of 1990 (ADA) has implemented legal measures to ensure equal opportunities for people with disabilities, including opportunities to participate in sport. Globally, Article 30 of the United Nations' Convention on the Rights of Persons with Disabilities states that people with disabilities have the right to participate in recreation, leisure, and sport (un.org, n.d.). Although legislation exists to ensure equal opportunities for people with disabilities, it has not reduced stigmas 
and discrimination against athletes with disabilities (Wilson \& Khoo, 2013).

Psychological barriers are another type of constraint that prevent athletes with disabilities from participation and competing in sport. Psychological barriers are barriers related to society's mindset, stereotypes, and service. Disability sport is stigmatized and not well-known because people are not informed. Disability sport content is not taught in the sport management college classroom at the rate of other sportrelated content (Pitts \& Shapiro, 2017), leaving aspiring sport management professionals without formal training on disability inclusion.

Sport organizations that do meet the structural and infrastructural demands for accessibility often are susceptible to unseen psychological barriers in the way they communicate or fail to communicate with people with disabilities. These organizations, according to Darcy et al. (2016), fall short of meeting a marketing strategy for customers or athletes with disabilities by not targeting campaigns to attract or serve that segment of the market. For example, an accessible athletic training facility may have structural accessibility but lack in service toward patrons with disabilities (Pate \& Wallace Carr, 2017). Even when athletes with disabilities do have access, many do not feel accepted as elite athletes, which Cottingham et al. (2016) and Hardin and Hardin (2004) described as barriers of legitimacy.
Included in psychological barriers is coaching. Athletes with disabilities have found themselves training without coaches who are qualified, which Martin and Whalen (2014) found to produce negative ramifications. Coaches of disability sport often face unique challenges, such as not understanding the athlete's disability (Martin \& Whalen, 2014), scarce resources and learning opportunities for coaches, and varying needs of coaches depending on how a sport is adapted (McMaster, Culver, \& Werthner, 2012). For example, McMaster et al. (2012) point out that adaptive rowing and sailing require specific adaptations for individual athletes based on their ability levels whereas wheelchair rugby, tennis, or basketball require minimal adaptive devices or altercations to the athlete's approach. McMaster et al. (2012) note that formalized coaching education programs are scarce for coaches without a disability who are coaching in disability sport, thus forcing them to learn through secondary experiences.

Psychological barriers also inhibit coaching in disability sport. Wareham, Burkett, Innes, and Lovell (2017) reported that disability sport coaches felt stigmatized, that coaching athletes with disabilities could damage their reputation as an elite coach, and that outsiders may question their capability as a coach because they were coaching athletes with disabilities. Furthermore, Wareham et al. (2017) found that coaches often feared 
they may push their athletes too hard and cause physical or psychological injury. These barriers, then, limit a coach's influence on the athlete.

\section{Disability Sport Facilitators}

Alternatively, access to elite coaching and guidance transforms into a facilitator for some competitive athletes with disabilities (Kean et al., 2017). Kean et al. (2017) found that successful programs for athletes with disabilities provide access to resources any other sport program would offer: athletic training, physiotherapists, and medical support. Furthermore, successful programs support athletes through biomechanical research for optimal improvement (Keogh, 2011) and have coaches welltrained in how to work with athletes with disabilities through inclusion and preferred language choices, which positively affect recruiting the athletes (Kiuppis, 2018).

Other facilitators for elite disability sport have been shown to be government support systems (Brittain \& Hutzler, 2009; Guan \& Hong, 2016; Kean et al., 2017; Wilson \& Khoo, 2013). However, Hammond and Jeanes (2017) found that mainstreaming disability sport toward an equal plane as able-bodied sport involved risks as well, such as reduced funding and limiting who can participate in disability sport. Conversely, mainstreamed sports have been reluctant to accept disability sport into their organizations (Thomas \& Guett, 2014). Given the number of barriers and requirements for facilitating success, ensuring growth in even the most successful or popular disability sport is no simple approach.

\section{Research Context}

Competitive wheelchair basketball has primarily been a sport suited for people with physical disabilities. Athletes with the following impairments are eligible to compete at the Paralympic level of wheelchair basketball: Ataxia, athetosis, hypertonia, impaired muscle power, impaired passive range of motion, leg length difference, and limb deficiency (International Paralympic Committee, n.d.; Keogh, 2011). Wheelchair basketball's classification system assigns points to each player between 1.0 and 4.5, with 1.0 representing the most limited activity. A team may only have a total of 14 points on the court at any given time (International Paralympic Committee, n.d.).

While necessary for ensuring inclusion and equal competition among teams, the classification system and eligibility requirements may also present limitations for those not eligible to compete or provide a competitive approach the game (ángel Gómez, Pérez, Molik, Szyman, \& Sampaio, 2014; Hindawi, Orabi, Arjan, Judge, Cottingham, \& Bellar, 2013; Vanlandewijck, Evaggeunou, Verellen, Houtte, Aspeslagh, \& Zwakhoven, 2003; 2004). Keogh (2011) highlighted a potential barrier of the classification system of penalizing athletes for their higher training status rather than their 
disability, because the functional system classifies athletes based on their ability of a variety of generic sporting tasks.

Classification systems within other elite competitive disability sports such as rugby have shown to be a barrier to participation, as well (Santos, Vigário, Mainenti, Ferreira, \& Lemos, 2017). Barriers such as these are necessary for competition, but ultimately present challenges to developing disability sport, specifically wheelchair basketball at the elite, competitive level within the United States. Furthermore, nuances of the game itself have been found to be a barrier, such as the fact that wheelchair basketball players shoot from a seated position to the same rim height as ambulatory basketball (Oudejans, Heubers, Ruitenbeek, \& Janssen, 2012).

In spite of the barriers the sport itself has, wheelchair basketball has been viewed as an amateur sport with elite and stable qualities often associated with professional sport. Hardin and Hardin (2003) found that media coverage of wheelchair basketball trivialized the sport by featuring it in the community section rather than sports section, and the researchers later found that athletes understood that being viewed as inspirational rather than for their athleticism could be to their advantage regarding visibility (Hardin \& Hardin, 2004). Still, athletes were frustrated that their sport was not received with respect that other sports garner (Hardin \& Hardin, 2003; 2004).
Research has supported the notion that wheelchair basketball is, indeed, amateur but with stability and structure that establishes credibility (Berger, 2008). Embracing the amateur status is one option to enhance validity for the sport. For example, Larkin, Cottingham, and Pate (2014) examined the feasibility of college wheelchair basketball teams competing under the NCAA structure and found that, due to Title IX and other funding constraints, women's wheelchair basketball may have grounds to apply as an emerging sport for women. Faull and Jones (2018) established and validated a tool to measure movement imagery for wheelchair sport athletes, recognizing the importance of mental skills training within disability sport. Common ties among this previous research reinforces that wheelchair basketball is an amateur system that operates with qualities of a stable structure.

\section{Theoretical Foundation}

Green's (2005) theory of sport development was chosen as the lens for this study because of its focus on establishment of a sport for sustainability through athlete participation. The theory argues that sport develops a broader acceptance by adopting policy through the pyramid model. The pyramid model addresses at least three key issues for athletes: Entrance, retention, and advancement.

Green argues that at least four concepts are required to analyze how 
individuals enter a sport: Recruitment, motivation, socialization, and commitment. Green points to soccer, swimming, and baseball as examples of sports that established youth leagues for children to develop a commitment to the sport before adolescence when other influential factors take over. Entrance for athletes at a later age may depend on sponsored recruitment - when significant others support and encourage athlete involvement - for sport development (Brodkin \& Weiss, 1990; Kay, 2000).

Green (2005) suggests that retention of athletes requires action from both the athlete and the program. Athletes must find value in the sport participation, whereas programs must focus on social interaction, fitness, skill development, and play while also catering to a range of athlete talent rather than just the average competitor (Green, 2005). Attracting athletes at all skill levels ensures greater promotion of health and fitness benefits (Seefeldt, 1986; Siedentop, 2002; Wang, Pratt, Macera, Zhi-Jie, \& Heath, 2004). Additionally, it enlarges the pool of athletes from which elite sport may eventually seek recruitment (Green \& Oakley, 2001; McNeill, Sproule, \& Horton, 2003).

Sport development is critical for the elite level of competition to elevate national prestige and strengthen sport as an international tool for relations and development (Houlihan, 1997). Furthermore, based on Green's pyramid model, the objective of sport development is to recruit athletes into the sport and advance some of them into high-caliber performers.

Given the length of time wheelchair basketball has operated at the elite, competitive level within the United States, and given the length of time the NWBA has served as the sport's governing body in North America, it may be assumed that the sport has achieved stability. However, the purpose of this study was to examine how the amateur sport of wheelchair basketball grows and thrives in recruiting and retaining participants. The setting for this study was within the NWBA with the following research questions guiding the work:

1. What are challenges faced by wheelchair basketball programs within the NWBA?

2. What are strategies for NWBA teams to recruit wheelchair basketball players with disabilities?

3. What are strategies for NWBA teams to retain wheelchair basketball players with disabilities?

For the purposes of this study, retention is when an athlete competed for a team one season and chose to return for a following season. RQ3 seeks to understand how teams ensure athletes return the following season.

\section{Methodology}

The NWBA included 139 teams across five divisions according to its website, www.nwba.org as of September 2017. Each program's team representative was contacted via e-mail with an invitation to participate in the 
study. E-mails were sent to 120 total contacts due to several teams having the same contact person (e.g., a college program with multiple teams but one primary contact). Seven e-mails were returned as undeliverable, leaving 113 e-mails that were successfully sent. Initial invitations were sent August 30, 2017. Reminder e-mails were sent one week later on September 6, 2017. The questionnaire was closed on September 15, 2017.

The questionnaire was developed based on the desire to address the research questions guiding the current study. A pilot questionnaire was sent to a disability sport advocate and nine-year wheelchair basketball program director for feedback. The questionnaire was adapted based on information received from the feedback and finalized for the study. Participants were invited to complete an online open-ended questionnaire focused on the profile of their wheelchair basketball program, the challenges their program faced, and recruitment and retention of athletes. Participants were not required to answer each question.

Data analysis began with open coding of the data, searching for basic concepts and categories within the data. Open coding was performed by highlighting similar text and assigning the group a code that best defined the concepts and categories. Analysis continued with axial coding where the researcher re-read the text to confirm open codes were accurate and examined how concepts were related. Similar concepts were grouped together and assigned an axial code that best described the grouped concept. From there, data were again examined to construct themes.

\section{Findings and Discussion}

There were 28 people who completed the questionnaire for a response rate of $24.8 \%$. A general overview of the respondents showed $39.3 \%$ were affiliated with a Division III team, which may be attributed to a number of factors. Division III is for newer players seeking competition for development and even recreation (NWBA, n.d.b). These respondents may be eager to become involved in NWBA-related activity, eager to share their experiences and challenges, and more eager to engage in discussion about their teams and players in hopes of advancing and creating awareness.

Respondents' teams were from 17 different states as well as Puerto Rico and Washington D.C. Professional titles and their affiliation with the team were mainly head coach $(n=12)$ and manager/coordinator $(n=8)$. The respondents had been affiliated with the team for an average of 7.63 years with a range of 1 year to 41 years. Respondents primarily held a bachelor's $(40.7 \%)$ or master's (44.4\%) degree. Around two-thirds of the participants $(66.7 \%)$ identified with having a disability.

\section{Team Profiles and Origins}

Teams averaged 13.7 players on the team with a range of 6-40. Programs 
were fairly recently started, with 14 having been formed since 2000, seven since 2014. Most programs (71.4\%) examined in this study were not affiliated with a college or university. Of the eight programs that were affiliated with a college or university, $50.0 \%$ offered partial scholarships; the other half offered no funding or another type of financial assistance such as athlete grants. None of the programs offered full scholarships. Of the remaining programs not affiliated with a college or university, $75.0 \%$ offered no funding for their players. Of the five programs that did provide funding for players, a range of 5-15 players received funding that ranged from as low as $\$ 50$ to as high as a $\$ 5,000$ grant.

Team origins were a mix among how they began: personal interest (8), addressing a community need/desire (5), affiliation with rehabilitation centers (4), affiliation with a university (2), evolution from a previous team (2), and unknown (1). Personal interest, community need, and rehabilitation center connections link to wheelchair basketball's history with injured World War II veterans who formed the first competitive team (NWBA, n.d.).

Green's (2005) first key policy issue of the pyramid model of sport development emphasizes athlete entrance into a sport; thus, identification of NWBA team origins in rehabilitation centers and universities establishes a system through which athletes can be funneled to ensure the sport continues development and a pipeline of athletes is established. Conversely, teams with roots in personal interest or community needs offer less structure for sustainable entrance into the sport and may consider alignment with an organization or support system for stronger connections to athletes.

The NWBA does not have policy specific to athlete entrance; however, team origins show a structure in place to ensure sustainability. People with disabilities will always be present in rehabilitation centers, which are using sport within the rehabilitation process. Similarly, people with disabilities will continue to seek higher education opportunities, and disability sport in a university setting can be used as a tool to provide those opportunities.

Both rehabilitation centers and universities are environments that foster sponsored recruitment, where athlete involvement is encouraged by significant others (Brodkin \& Weiss, 1990; Kay, 2000). Individuals in rehabilitation centers can be surrounded by family and others supporting their rehab efforts, of which sport may be part. Individuals in a college setting may be supported both financially by scholarship and psychologically by family. Establishing programs supported by rehabilitation center and university infrastructure is vital because wheelchair basketball is missing established youth leagues like more traditional American sports with a system for advancement and athlete development (e.g., soccer, baseball; 
Green, 2005). Still, it is unclear how many current wheelchair basketball players in the NWBA may have been eligible for a youth program due to when they acquired a disability.

\section{Challenges Teams Face}

Addressing RQ1, the biggest challenge teams identified was funding to support travel and athletes, as well as the challenge of recruiting and retaining athletes to play wheelchair basketball without offering financial incentive or reward. While understanding recruitment and retention strategies were within the purpose of the current study, participants identifying both as a challenge was not assumed or anticipated.

We have immense difficulty finding funding. We want to travel for more tournaments (particularly because the women's teams are spread all over the country and playing against them always requires travel), but we need more funding for this. Our women are not able to pay out-of-pocket for travel.

Scholarships. Our team is funded well for what we need (travel, equipment, etc.). But we are way behind when it comes to scholarships or out-of-state tuition waivers. We have had a number of top recruits love our campus, love our program, but cannot commit because they are being offered scholarships to play somewhere else. Hard for us to compete against that.

We are not new any longer, so our team is more competitive and ready to make a push for nationals, but our budgets have been cut and in reality, we have less money today than when we started the program. Inexpensive gym space, funding support for tournaments, getting teams to come to [city] for tournaments, and keeping adults consistently engaged.

Funding, competing against larger universities with scholarship money and bigger budgets.

Scholarship funding, access to campus resources on par with our able-bodied athletics programs.

See Table 3 for a complete list of participant quotes and their assigned themes regarding challenges their teams face.

\section{How Teams Recruit Athletes}

Addressing RQ2, teams primarily recruit athletes through social avenues such as word-of-mouth and social media presence, as well as community presence and traditional athlete recruiting visits (see Table 4).

We ask anyone who looks like they have a disability that we happen to see in our communities. 


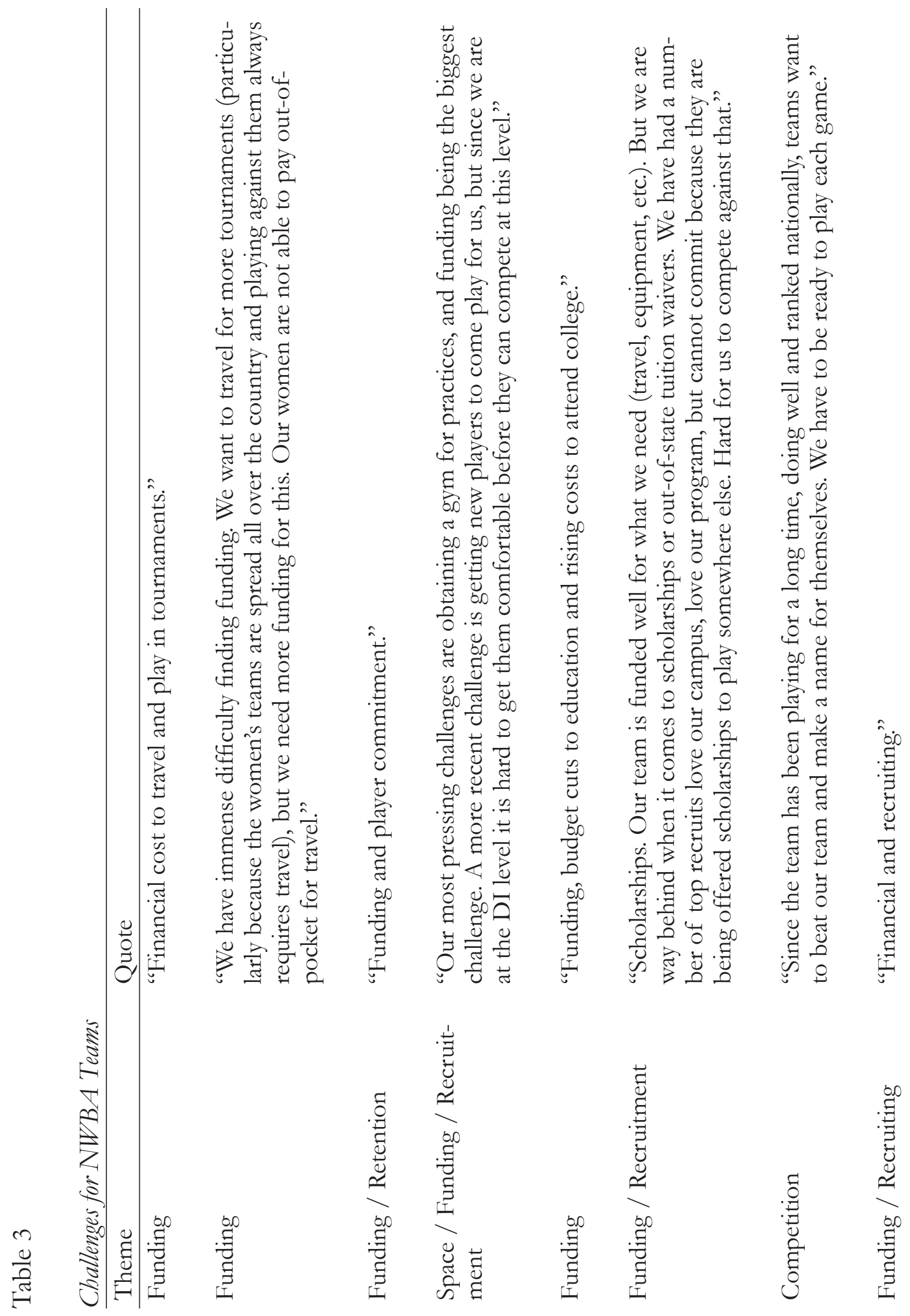

Journal of Amateur Sport $\quad$ Volume Five, Issue One $\quad$ Pate and Bragale, 2019 


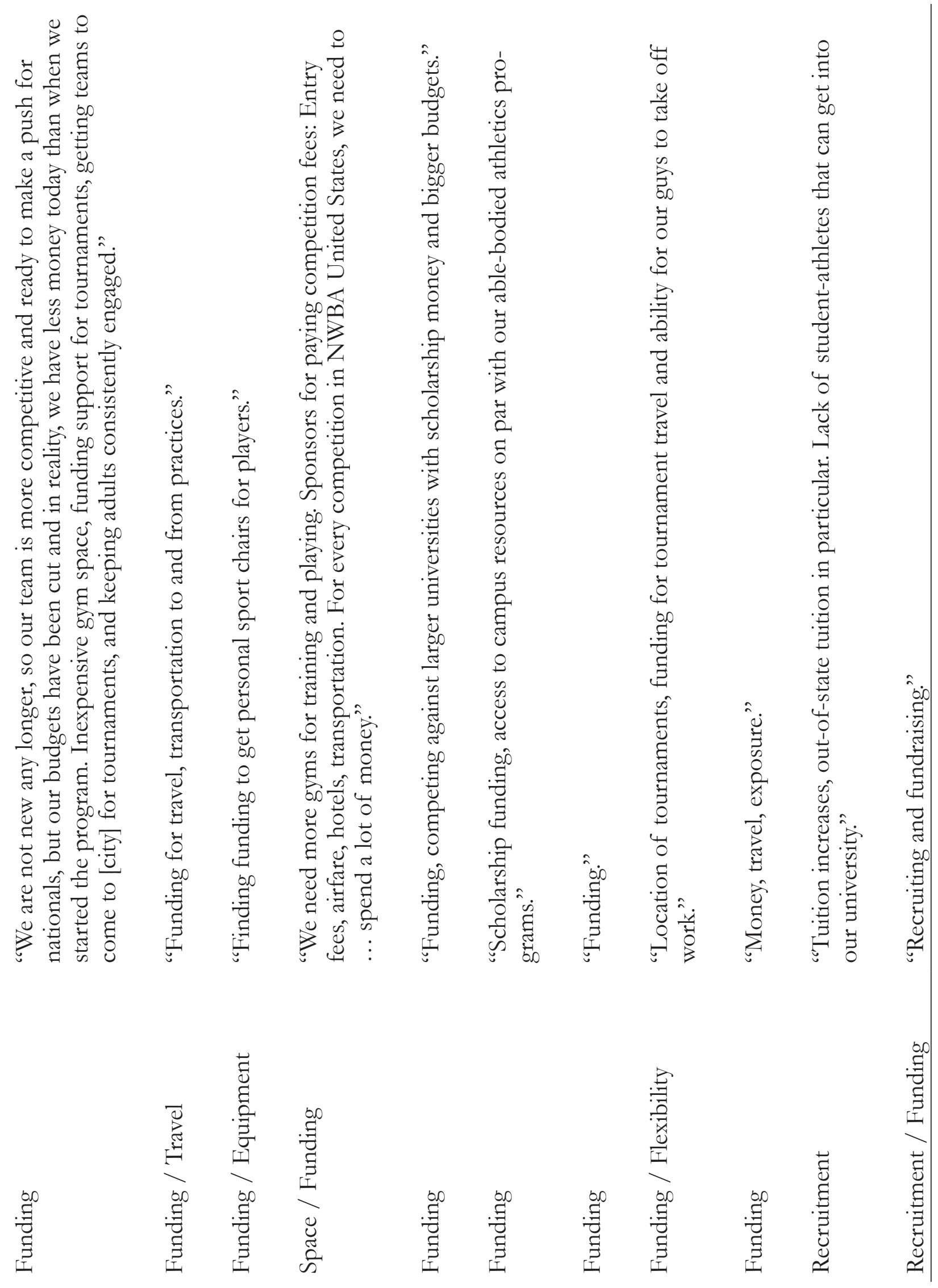

Journal of Amateur Sport $\quad$ Volume Five, Issue One $\quad$ Pate and Bragale, $2019 \quad 62$ 


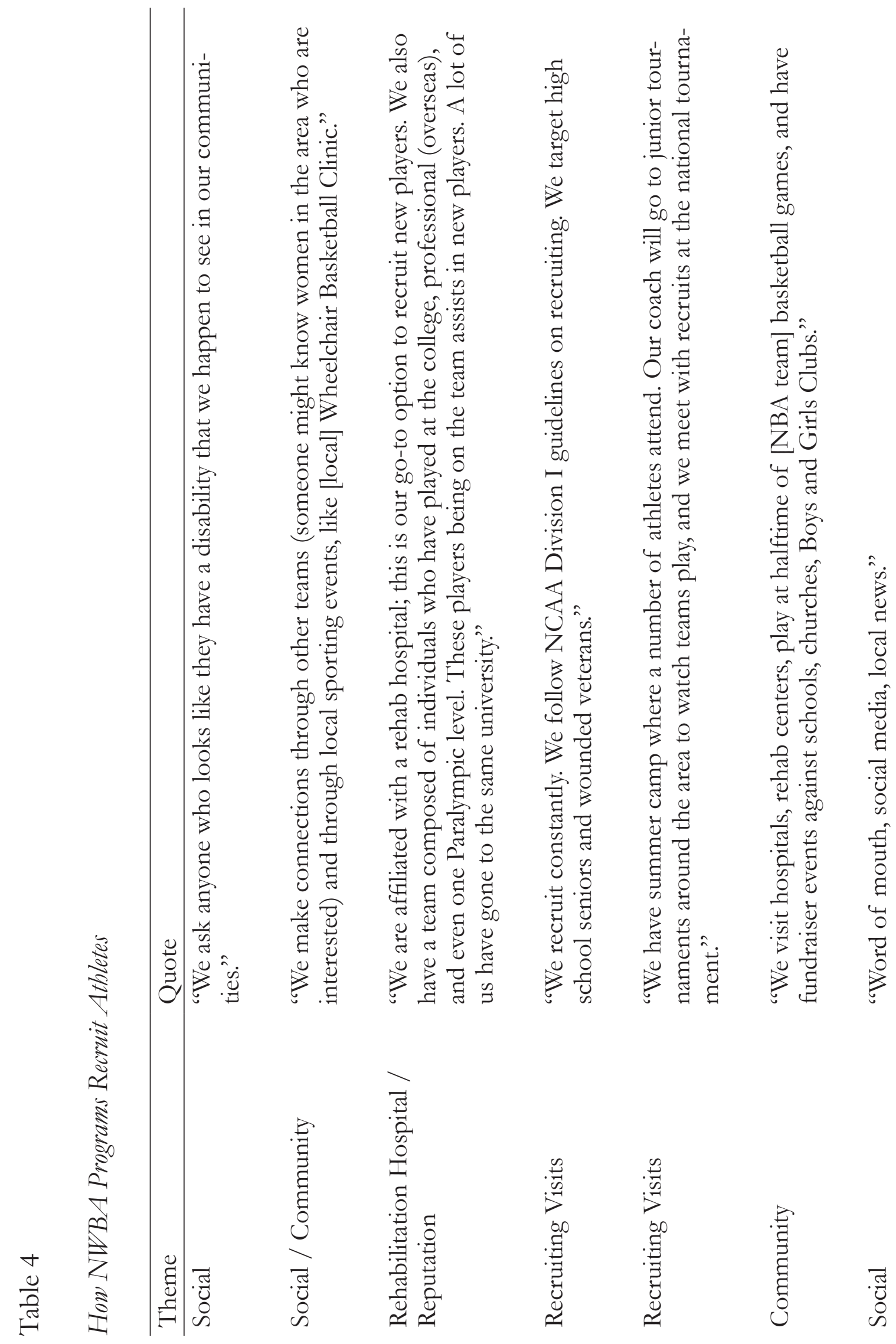

Journal of Amateur Sport $\quad$ Volume Five, Issue One $\quad$ Pate and Bragale, 2019

63 


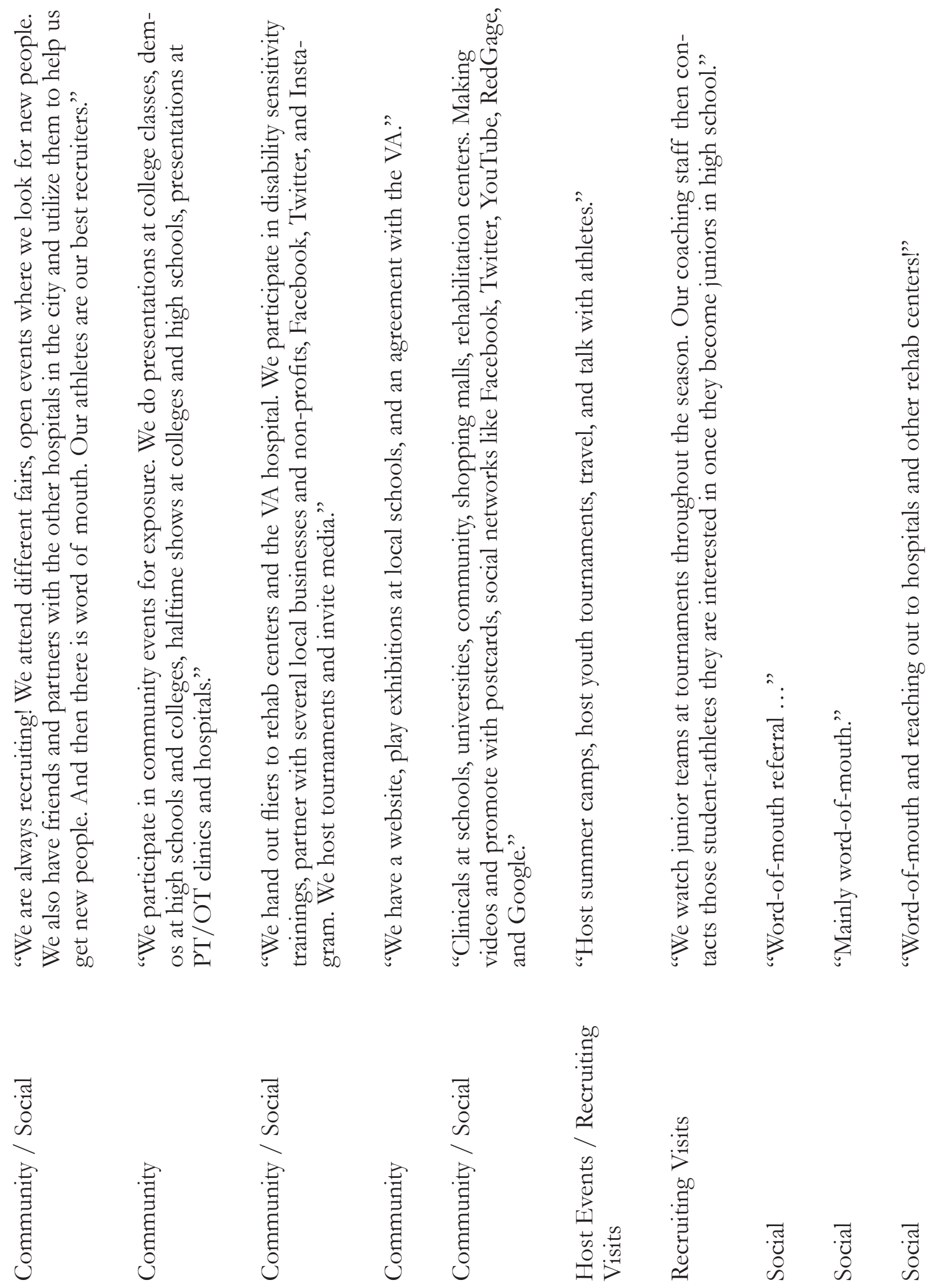

Journal of Amateur Sport Volume Five, Issue One

Pate and Bragale, 2019

64 


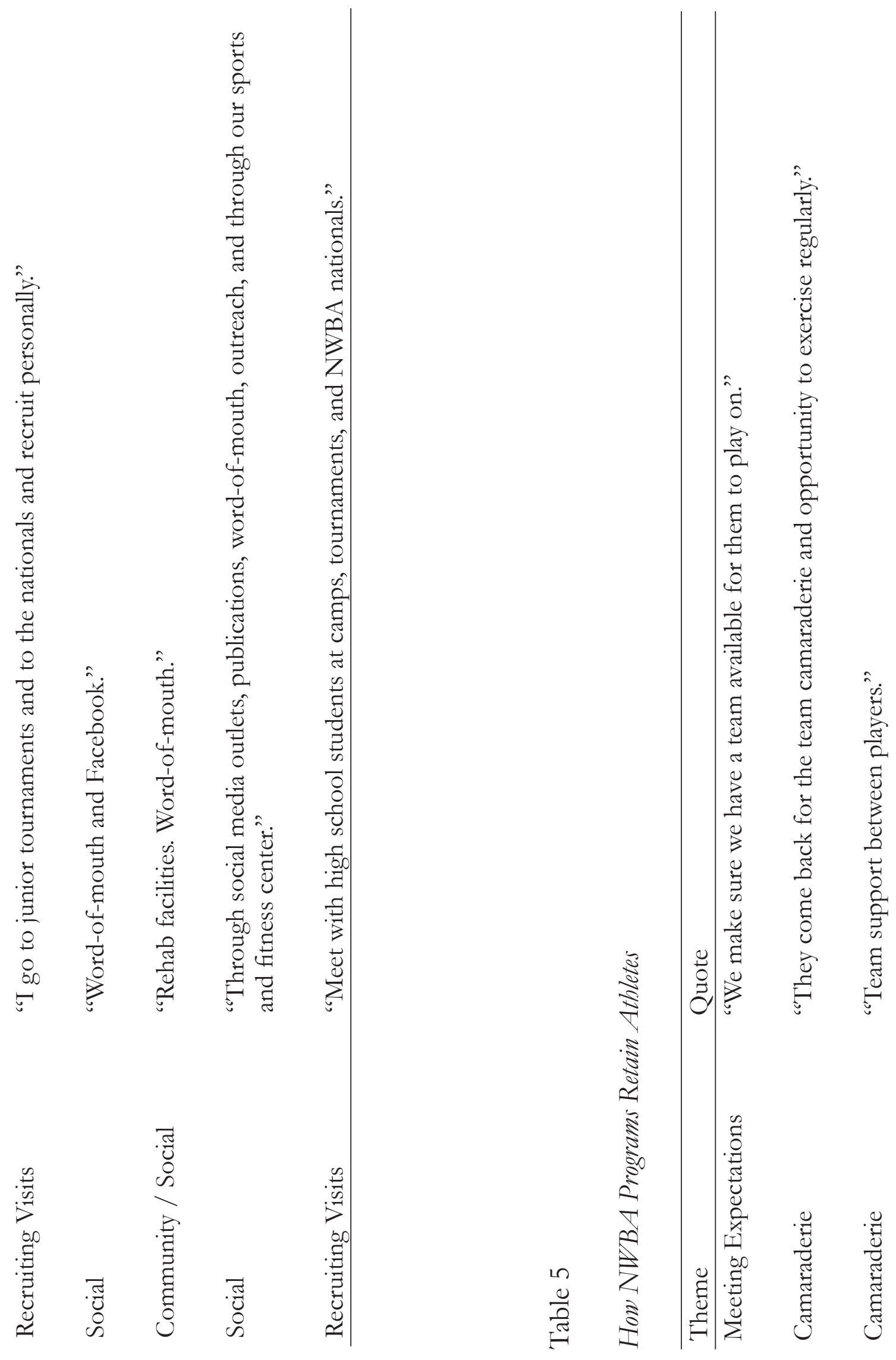

Journal of Amateur Sport $\quad$ Volume Five, Issue One $\quad$ Pate and Bragale, 201965 


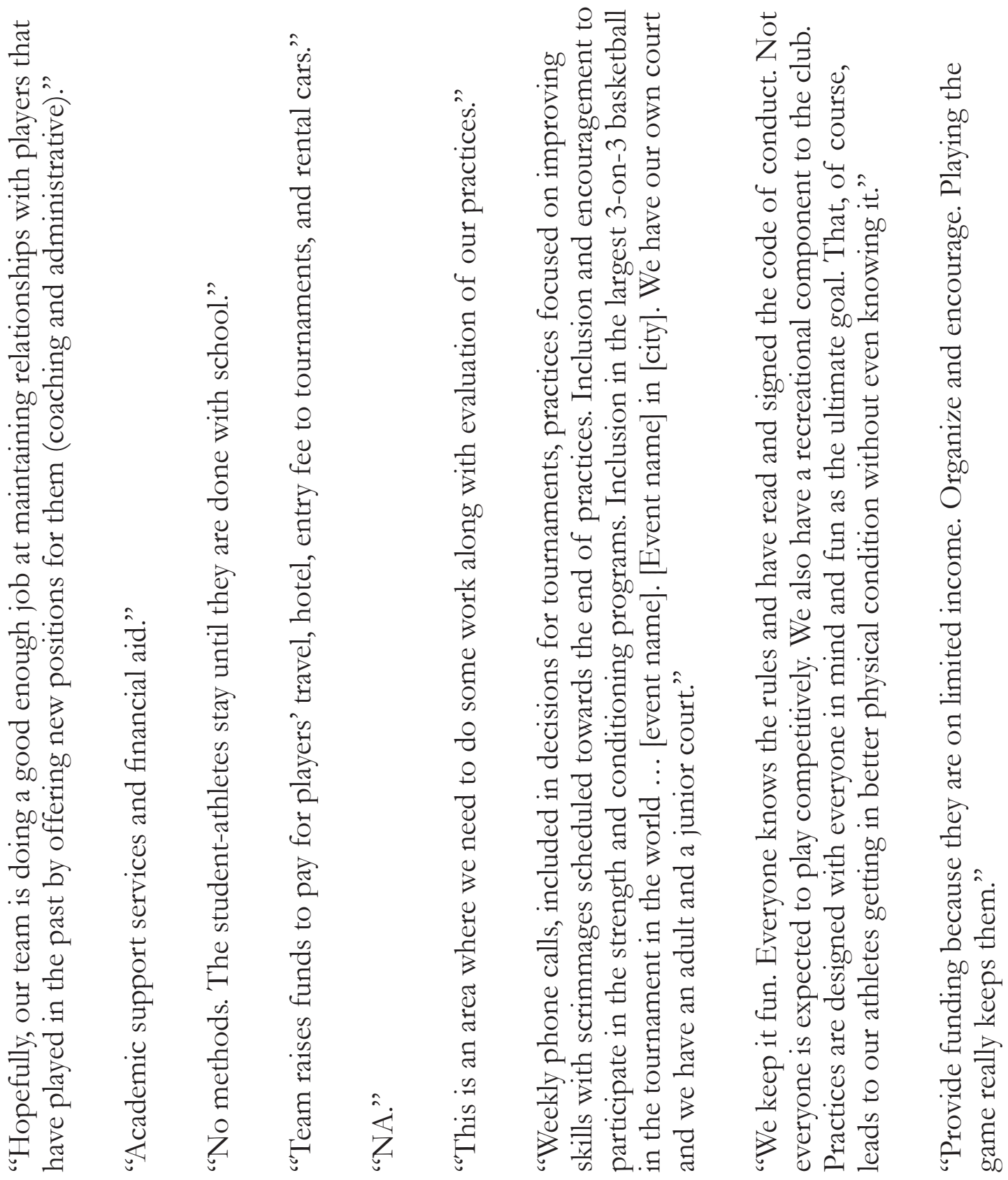

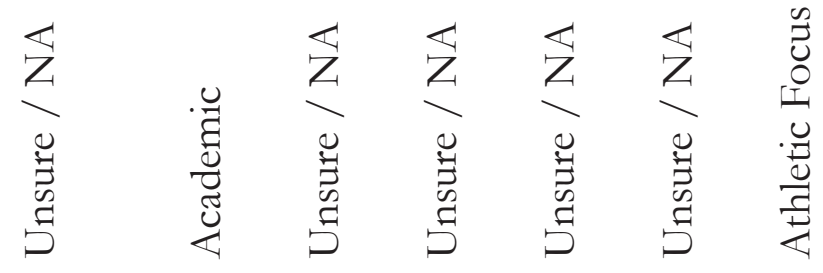

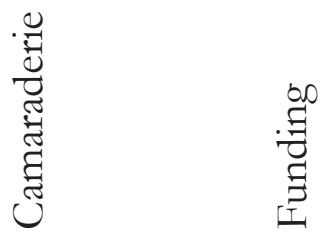

Journal of Amateur Sport $\quad$ Volume Five, Issue One $\quad$ Pate and Bragale, 201966 


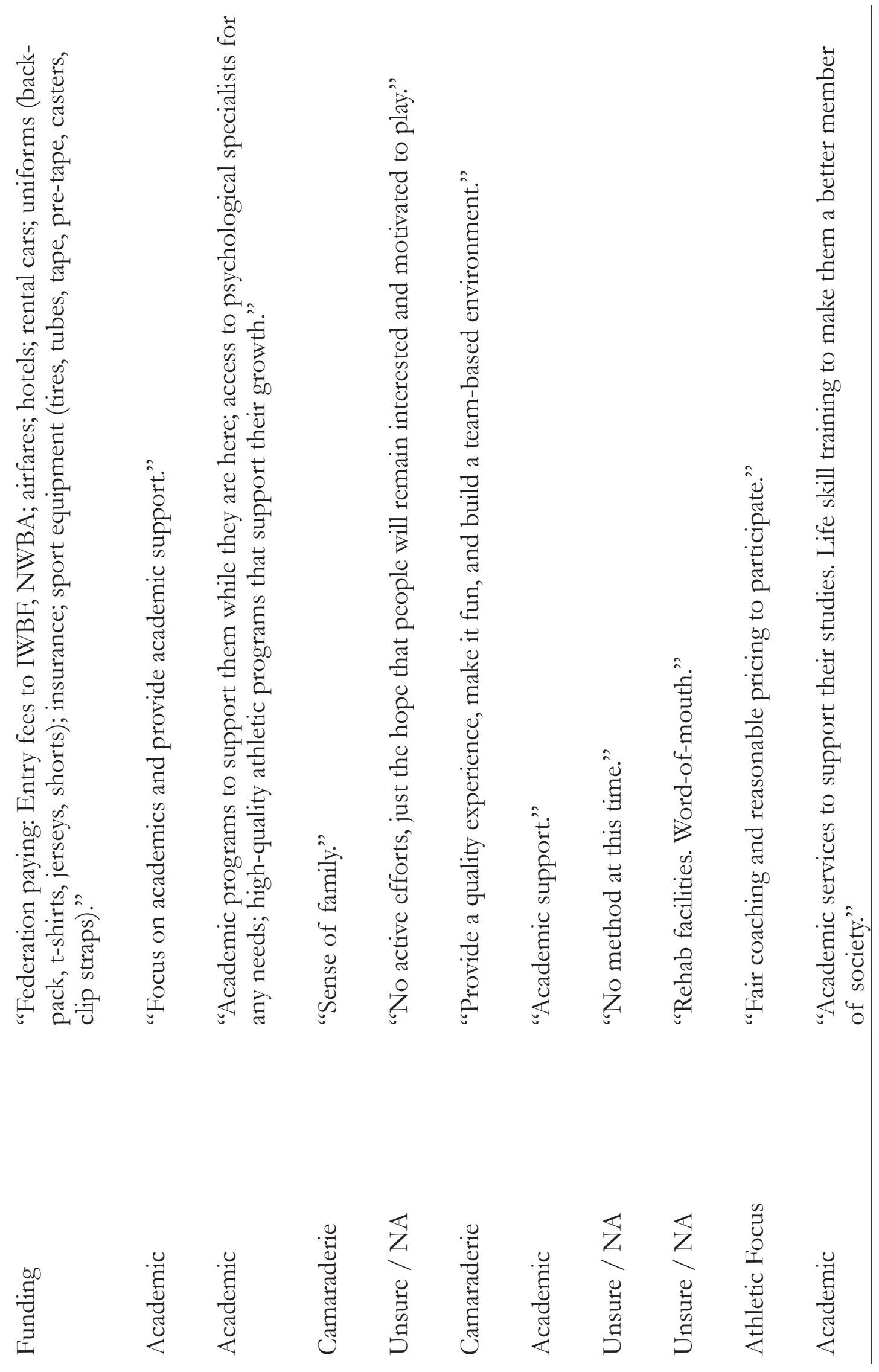

Journal of Amateur Sport $\quad$ Volume Five, Issue One $\quad$ Pate and Bragale, $2019 \quad 67$ 
We make connections through other teams (someone might know women in the area who are interested) and through local sporting events, like [local] Wheelchair Basketball Clinic.

We visit hospitals, rehab centers, play at halftime of [NBA team] basketball games, and have fundraiser events against schools, churches, Boys and Girls Clubs.

We recruit constantly. We follow NCAA Division I guidelines on recruiting. We target high school seniors and wounded veterans.

We watch junior teams at tournaments throughout the season. Our coaching staff then contacts those student-athletes that are interested in once they become juniors in high school.

\section{How Teams Retain Athletes}

In response to RQ3 and how teams retain athletes, a number of participants indicated they were unsure, it did not apply to them, or they had no determined strategy to retain their athletes. This response is not surprising for college-affiliated teams that may have scholarship options or captive participants who are enrolled in a university. Scholarships are annually renewed, but university enrollment serves as a natural retention strategy as students return for their sequential semester of college. Those who did focus on retaining athletes identified athlete camaraderie as well as offering academic support services for athletes in a university setting (see Table 5). No active efforts, just the hope that people will remain interested and motivated to play.

This is an area where we need to do some work along with evaluation of our practices.

They come back for the team camaraderie and opportunity to exercise regularly.

Team support between players.

Academic programs to support them while they are here; access to psychological specialists for any needs; high-quality athletic programs that support their growth.

Academic services to support their studies. Life skill training to make them a better member of society.

\section{Application to Theory of Sport Development}

Green's (2005) pyramid model suggests that action is required from both the athlete and the program for sport development. According to Green, athletes must find value in participation, and that is seen through the challenges NWBA programs identified such as 
funding. Funding has been among the primary challenges for all disability sport (Rimmer et al., 2004; Wilson \& Khoo, 2013). More specifically, travel funding for competition and basic participation has been identified as a barrier for disability sport (Cottingham et al., 2016; Darcy et al., 2016; Kean et al., 2017), as was identified by participants in the current study.

While no program may be immune to such a financial challenge, participants in the current study noted the funding challenge has prevented them from recruiting athletes to play wheelchair basketball as well as retaining them through a financial incentive. This recruitment challenge relates to Cottingham et al.'s (2016) finding that underemployment of people with disabilities presents financial barriers that may prevent sport participation. Applied to the current study, athletes without proper employment - or a consistent income - may not be available for participation on an NWBA team due to lack of financial support.

Green (2005) contends that programs must emphasize social interaction and personal development for a variety of athletic skill levels. Kean et al. (2017) found that athletes seek greater athletic and personal development within the connections of a team. NWBA teams that operate as part of a more comprehensive wheelchair basketball program with multiple levels of participation (e.g., youth, developmental, professional) are at an advantage for recruitment and retention, according to Green's pyramid model, because it promotes broader health and fitness while recruiting young athletes into the pipeline for the elite level.

Similarly, findings from the current study showed that universityaffiliated NWBA programs expose athletes to resources on campus that support their athletic, academic, and personal development through elite training, tutors, and personal growth opportunities, respectively. This supports Green's objective for sport development: to recruit athletes into a sport and advance them into high-performers.

Prior literature related to barriers and challenges in disability sport suggested that communication with the disability population has been inconsistent or incorrect through areas of marketing to the disability population or even reporting on disability sport (Darcy et al., 2016; Hardin \& Hardin, 2003; 2004), service quality (Pate \& Wallace Carr, 2017), and acceptance in a social setting (Cottingham et al., 2016). Furthermore, elite coaching (Martin \& Whalen, 2014), ability for coaches to adapt their approach (McMaster et al., 2012), and coaches inheriting stigma of disability sport (Wareham et al., 2017) have shown to be barriers within disability sport. None of these were supported through the current study as challenges to NWBA teams regarding their ability to recruit and retain athletes. Participants in this study showed no indication of validation as a barrier to their success (Cottingham 
et al., 2016), which is a sign of the sport's acceptance and increasing stability.

\section{Conclusion}

The NWBA has operated as a competitive wheelchair basketball league since 1946 and endured growth that indicates sustainability for both the sport and the league. Deeper exploration into the challenges and barriers NWBA teams face, however, reveals that annual operation of a wheelchair basketball team faces challenges akin to amateur sport due to the structural barrier of funding. Funding may be a challenge many sports face, but unique to wheelchair basketball is the travel required to compete in tournaments due to transportation costs and entry fees unseen under the collegiate or professional structure of most sports.

Other structural barriers such as facility accessibility and equipment access were not prominent findings from the current study, nor were psychological barriers. Thus, it is important to note the structural barrier of funding emerges as the most important barrier in competitive wheelchair basketball in order to ensure sustainable programs for athletes.

There must be a strong infrastructure and a sustainable funding plan in place for an elite competitive wheelchair basketball team to succeed because resources and recruiting athletes are among the biggest challenges. NWBA teams that originated from an existing infrastructure of a rehabilitation hospital or a university recreation department reduce the barrier of facility and equipment access. This type of infrastructure offers a solid foundation for teams, but it has not guaranteed sustainable success through funding and therefore reinforces an amateur status.

NWBA teams recruit primarily through social connections such as wordof-mouth and social media presence while also attempting to be visible within their communities. This approach to recruiting athletes is opposite of traditional athletic programs that sign players into financial agreements for their sport services (e.g., scholarships at universities or contracts with professional teams). While some teams do have financial resources for scholarships and/ or financial payment for athletes, the majority do not and rely on athletes' dedication to the sport to lure them into playing for the team. Therefore, the social connections and community visibility become the primary recruiting tool for teams rather than the traditional means of recruiting.

Flipping the recruitment strategy makes retaining players a challenge for some teams. Nearly one-third of participants in the current study did not identify a strategy to retain their players, which is a sign of poor strategy and complacency for collegiate programs. Collegiate programs may have the university structure in place for ensuring athletes are back for another semester, 
but guaranteeing a consistent pipeline of athlete interest is risky. Among those participants who did offer a strategy, it primarily involved building relationships with teammates and offering personal support services (e.g., academic services for university-affiliated teams). Thus, teams are relying on soft connections rather than contracts to keep their team functioning as a unit on an annual basis. Such a strategy is also risky considering the financial instability of people with disabilities (Cottingham et al., 2016).

Given the challenges of wheelchair basketball's longevity (Hutzler et al., 2016), growth and expansion must take into consideration that insufficient planning for team sustainability (e.g., funding and retaining athletes) may not bode well for success of the sport or the NWBA. Implications to consider from this study are that teams should align with existing community organizations that can leverage funding for grants and scholarships while also providing community visibility. This type of alignment will work to address the weak infrastructure for those teams started from community needs or personal interest in order to establish a longterm presence beyond that of the initial interesting party. Furthermore, it can establish credible funding opportunities and community presence that work to both recruit and retain athletes through a more robust pipeline for future athlete entrance and commitment to this amateur sports league.

\section{Limitations and Future Research}

As with any research, there were limitations to the current study that primarily focused on the sample and their responses. The 28 participants offered insight into the challenges and recruitment and retention strategies for teams in the NWBA. However, their responses were not detailed and the online questionnaire was not an environment that promoted dialogue between the researchers and participants for follow-up inquiry. This would have provided richer data with perhaps greater insight particularly into the funding challenges that teams face. The researchers invited participants to participate in a follow-up semi-structured telephone interview, but those who indicated interest did not respond to researchers' e-mails.

Furthermore, 28 responses leaves 111 NWBA teams that did not have representation in this study. Therefore, it is difficult to generalize these findings to all NWBA teams. Generalization, however, is not a primary feature of qualitative study. Finally, the challenges that NWBA teams face may not necessarily be representative of the challenges that all wheelchair basketball teams outside of the league face, regardless of the level of play.

The findings of this study did reveal a greater need for exploration into the funding models that wheelchair basketball teams follow since financial security was identified as the primary challenge. Participants in this study 
indicated their teams either did not offer funding for athletes, offered some form of scholarship support, or offered some form of grant funding. Greater insight into a preferred model of funding for teams and their athletes is necessary to fully explore wheelchair basketball through the sport development model.

Finally, the current study revealed that participants did not have a clear strategy for retaining athletes. Greater research is necessary to explore team community and camaraderie, as the current study identified this as a means of retaining athletes. Despite roots in strong infrastructure such as universities and rehabilitation centers, participants' lack of strategy to retain athletes revealed the potential for an inconsistent future for the team.

Understanding community and camaraderie on a team may allow other teams to secure their athlete retention strategies for a stronger future under the present circumstances the league faces as an organization operating under amateur sport constraints. Furthermore, investigation into the makeup of athletes on wheelchair basketball teams may lead to greater understanding of when and how athletes can get involved in wheelchair basketball via youth programming and education to further enhance a system of stability and growth.

\section{References}

ángel Gómez, M., Pérez, J., Molik, B.,

Szyman, R. J., \& Sampaio, J. (2014).

Performance analysis of elite men's and women's wheelchair basketball teams. Journal of Sports Sciences, 32(11), 1066-1075.

Berger, R. J. (2008). Disability and the dedicated wheelchair athlete: Beyond the "supercrip" critique. Journal of Contemporary Ethnography, 37(6), 647678.

Cottingham, M., Carroll, M., Lee, D., Shapiro, D., \& Pitts, B. (2016). The historical realization of the Americans with Disabilities Act on athletes with disabilities. Journal of Legal Aspects of Sport, 26, 5-21.

Brittain, I., \& Hutzler, Y. (2009). A social-historical perspective on the development of sports for persons with physical disability in Israel. Sport in Society, 12(8), 1075-1088.

Brodkin, P., \& Weiss, M. R. (1990). Developmental differences in motivation for participating in competitive swimming. Journal of Sport \& Exercise Psychology, 12(3), 248-263.

Burkett, B. (2010). Technology in Paralympic sport: Performance enhancement or essential for performance? British Journal of Sports Medicine, 44(3), 215-220.

Darcy, S., Lock, D., \& Taylor, T. (2016). Enabling inclusive sport participation: Effects of disability and support needs on constraints to sport participation. Journal of Leisure Sciences, 39, 20-41.

Faull, A. L., \& Jones, E. S. (2018). Development and validation of the Wheelchair Imagery Ability Questionnaire (WIAQ) for use in 
wheelchair sports. Psychology of Sport and Exercise, 37, 196-204.

Green, B. C. (2005). Building sport programs to optimize athlete recruitment, retention, and transition: Toward a normative theory of sport development. Journal of Sport Management, 19(3), 233-253.

Green, M., \& Oakley, B. (2001). Elite sport development systems and playing to win: Uniformity and diversity in international approaches. Journal of Leisure Studies, 20(4), 247267.

Guan, Z., \& Hong, F. (2016). The development of elite disability sport in China: A critical review. The International Journal of the History of Sport, 33(5), 485-510.

Hammond, A., \& Jeanes, R. (2017). Federal government involvement in Australian disability sport, 1981-2015. The International Journal of the History of Sport. Retrieved August 8, 2018, from https://www.tandfonline.com/doi/ab s/10.1080/09523367.2017.1337000

Hardin, B., \& Hardin, M. (2003). Conformity and conflict: Wheelchair athletes discuss sport media. Adapted Physical Activity Quarterly, 20, 246-259.

Hardin, M., \& Hardin, B. (2004). The "supercrip" in sport media: Wheelchair athletes discuss hegemony's disabled hero. Sociology of Sport Online, 7(1). Retrieved December 19, 2018, from http://psysed.otago. ac.nz/sosol/v7il/v7il_1.html

Hindawi, O. S., Orabi, S., Arjan, J., Judge, L. W., Cottingham, M., \& Bellar, D.
M. (2013). Offensive tactical thinking level of wheelchair basketball players in Arab countries. European Journal of Sport Science, 13(6), 622-629.

Houlihan, B. (1997). Sport, national identity and public policy. Journal of the Association for the Study of Ethnicity and Nationalism, 3, 113-137.

Hutzler, Y., Barda, R., Mintz, A., \& Havosh, T. (2016). Reverse integration in wheelchair basketball: A serious leisure perspective. Journal of Sport and Social Issues, 40(4), 338-360.

International Paralympic Committee. (n.d.). Classification. Retrieved July 20, 2018, from https://www.paralympic. org/wheelchair-basketball/ classification

Kay, T. (2000). Sporting excellence: A family affair? European Physical Education Review, 6, 151-169.

Kean, B., Gray, M., Verdonck, M., Burkett, B., \& Oprescu, F. (2017). The impact of the environment on elite wheelchair basketball athletes: A cross-case comparison. Qualitative Research in Sport, Exercise and Health, 9(4), 485-498.

Keogh, J. W. L. (2011). Paralympic sport: An emerging area for research and consultancy in sports biomechanics. Sports Biomechanics, 10(3), 234-253.

Kiuppis, F. (2018). Inclusion in sport: Disability and participation. Sport in Society, 21, 4-21.

Larkin, B., Cottingham, M., \& Pate, J. R. (2014). Exploring the legitimacy of wheelchair basketball as an NCAA emerging sport. Journal for the Study of 
Sports and Atbletes in Education, 8(3), 168-185.

Martin, J. J., \& Whalen, L. (2014).

Effective practices of coaching disability sport. European Journal of Adapted Physical Activity, 7(2), 13-23.

McMaster, S., Culver, D., \& Werthner, P. (2012). Coaches of athletes with a physical disability: A look at their experiences. Qualitative Research in Sport, Exercise and Health, 4(2), 226243.

McNeill, M., Sproule, J., \& Horton, P. (2003). The changing face of sport and physical education in postcolonial Singapore. Sport, Education and Society, 8, 35-56.

$\mathrm{Ng}$, P. (2007). Recruitment of disabled athletes: Hong Kong perspective. Journal of Physical Education \& Recreation (10287418), 13(1), 58-65.

NWBA. (n.d.a). History. Retrieved on June 12, 2018, from https://www. nwba.org/history

NWBA. (n.d.b). Adult Division III. Retrieved on December 18, 2018, from https://www.nwba.org/page/ show/4318239-division-iii

Oudejans, R. R., Heubers, S., Ruitenbeek, J. J., \& Janssen, T. W. (2012). Training visual control in wheelchair basketball shooting. Research Quarterly for Exercise and Sport, 83(3), 464-469.

Pate, J. R., \& Wallace Carr, J. (2017). Exercising inclusion: A case study exploring a fitness center staff's approach toward serving clients with disabilities. Global Sport Business Journal, 5(3), 52-65.
Pitts, B. G., \& Shapiro, D. R. (2017). People with disabilities and sport: An exploration of topic inclusion in sport management. Journal of Hospitality, Leisure, Sport \& Tourism Education, 21,33-45.

Rimmer, J. H. (2015). Physical activity for people with disabilities: How do we reach those with the greatest need? Institute of Medicine, Washington, D.C. Retrieved from http://nam. edu/wp-content/uploads/2015/06/ PAandDisabilities.pdf

Rimmer, J. H., Riley, B., Wang, E., Rauworth, A., \& Jurkowski, J. (2004). Physical activity participation among persons with disabilities: Barriers and facilitators. American Journal of Preventive Medicine, 26(5), 419-425.

Santos, P. R., Vigário, P. S., Mainenti, M. M., Ferreira, A. S., \& Lemos, T. (2017). Seated limits-of-stability of athletes with disabilities with regard to competitive levels and sport classification. Scandinavian Journal of Medicine \& Science in Sports, 27(12), 2019-2026.

Seefeldt, V. (1986). Physical Activity \& Well-being. Reston, VA: AAHPERD.

Siedentop, D. (2002). Content knowledge for physical education. Journal of Teaching in Physical Education, 21, 368377.

Strohkendl, H. (1996). The $50^{\text {th }}$ anniversary of wheelchair basketball: A history. New York: Waxmann Publishing. Thomas, N., \& Guett, M. (2014).

Fragmented, complex and cumbersome: A study of disability 
sport policy and provision in Europe. International Journal of Sport Policy and Politics, 6(3), 389-406.

Un.org. (n.d.). Article 30 - Participation in cultural life, recreation, leisure and sport. Retrieved July 11, 2018, from https://www.un.org/development/ desa/disabilities/convention-on-therights-of-persons-with-disabilities/ article-30-participation-in-culturallife-recreation-leisure-and-sport.html Vanlandewijck, Y. C., et al. (2003). Proportionality in wheelchair basketball classification. Adapted Physical Activity Quarterly, 20(4), 369.

Vanlandewijck, Y. C., et al.. (2004). The relationship between functional potential and field performance in elite female wheelchair basketball players. Journal of Sports Sciences, 22(7), 668-675.

Wang, G., Pratt, M., Macera, C. A., ZhiJie, M., \& Heath, G. (2004). Physical activity, cardiovascular disease, and medical expenditures in U.S. adults. Annals of Behavioral Medicine, 28(2), 88-94.

Wareham, Y., Burkett, B., Innes, P., \& Lovell, G. P. (2017). Coaching athletes with disability: Preconceptions and reality. Sport in Society, 20(9), 11851202.

Wilson, N. C., \& Khoo, S. (2013). Benefits and barriers to sports participation for athletes with disabilities: The case of Malaysia. Disability \& Society, 28(8), 1132-1145. doi:10.1080/09687599.2012.758034 